\title{
Scaling Leaf Measurements to Estimate Whole Canopy Gas Exchanges of Cotton
}

\author{
Dennis C. Gitz III, Jeffrey T. Baker, Robert J. Lascano \\ Wind Erosion and Water Conservation Unit, Cropping Systems Research Laboratory, USDA-ARS ${ }^{1}$, Lubbock, TX, USA \\ Email: dennis.gitz@ars.usda.gov
}

How to cite this paper: Gitz III, D.C., Baker, J.T. and Lascano, R.J. (2016) Scaling Leaf Measurements to Estimate Whole Canopy Gas Exchanges of Cotton. American Journal of Plant Sciences, 7, 1952 1963.

http://dx.doi.org/10.4236/ajps.2016.714178

Received: September 11, 2016

Accepted: October 8, 2016

Published: October 11, 2016

Copyright $\odot 2016$ by authors and Scientific Research Publishing Inc. This work is licensed under the Creative Commons Attribution International License (CC BY 4.0).

http://creativecommons.org/licenses/by/4.0/

(c) (i) Open Access

\begin{abstract}
Diurnal leaf and canopy gas exchanges of well-watered field grown cotton were measured. Our objective was to scale leaf-level values of transpiration and net assimilation to the whole canopy level using estimates of canopy leaf area. Single leaf gas exchange measurements were made with two portable photosynthesis systems and canopy measurements with four open Canopy Evapo-Transpiration and Assimilation (CETA) chamber systems. Canopy leaf area was measured at the end of the experiment and estimated during gas exchange by fitting values to a growth curve. Leaf level measurements were arithmetically scaled to estimate canopy level gas exchange based on canopy leaf area and then compared to the measured values. Scaled values of single leaf transpiration were very similar to canopy transpiration measurements, although both whole canopy transpiration and assimilation were overestimated around mid-day. We conclude that canopy cotton transpiration of well-watered field grown plants could be estimated within $5 \%$ throughout the day by scaling leaf level measurements to the whole canopy using measured canopy leaf area. Estimating canopy assimilation from leaf level measurements remains problematic.
\end{abstract}

\section{Keywords}

Cotton, Gossypium hirsutum, Scaling, Assimilation, Transpiration, Drought Stress

\footnotetext{
${ }^{1}$ The U.S. Department of Agriculture (USDA) prohibits discrimination in all its programs and activities on the basis of race, color, national origin, age disability, and where applicable, sex, marital status, familial status, parental status, religion, sexual orientation, genetic information, political beliefs, reprisal, or because all or part of an individual's income is derived from any public assistance program. (Not all prohibited bases apply to all programs.) Persons with disabilities who required alternative means for communication of program information (Braille, large print, audiotape, etc.) should contact USDA's TARGET Center at (202) 720-2600 (voice and TDD). To file a complaint of discrimination, write to USDA, Office of Civil Rights, 1400 Independence Avenue, S.W., Washington DC 20250-9410, or call (800) 795-3272 (voice) or (202) 720-6382 (TDD). USDA is an equal opportunity provider and employer.
} 


\section{Introduction}

Crop production is restricted to a range of suitable environmental conditions in which the plants are able to function. It follows that there exists a set of environmental conditions within which a crop functions optimally, resulting in maximal potential harvestable yield. Deviations from optimal conditions lead to reduced crop yields. Since crop yield is the product of plant function, agronomic "plant stress" can be defined as a reduction in realized yield resulting from sub-optimal whole plant physiological, metabolic, or developmental processes. So, managing agronomic system inputs such as irrigation water to maximize crop yield is an exercise in managing plant stress.

Crop water availability is one of the few environmental variables feasibly controlled at daily or hourly time steps at agronomic or horticultural production scales, with the notable exception of nutrient supplementation by fertigation [1]-[3]. Advances in irrigation technology associated with subsurface drip irrigation (SDI) allow for increasingly fine control of both the timing and amount of irrigation water applied to field crops, especially as compared to furrow and center pivot irrigation schemes, assuming adequate water availability to meet crop demand. The ability to more precisely control water delivery at shorter time scales has, in part, given impetus to development of plant based irrigation management [4]. Plant based irrigation scheduling seeks to determine the strain within the production system resulting from organismal water deficits, rather than the environmental conditions surrounding the crop; henceforth "Plant Stress" will continue to be used herein because it is a commonly used term. But it should be borne in mind that "Biological Strain" more accurately describes organismal responses and physiological dysfunction in response to sub-optimal environmental conditions and to specific stressors [5].

While physiologically based plant stress sensing schemes incorporate well recognized mechanistic principles for near real time assessment of water deficits, attempts to schedule irrigation by directly measuring physiological or metabolic processes directly related to crop performance such as net assimilation, transpiration rates, or stomatal resistance to carbon assimilation remain uncommon. Instead, an attempt to schedule irrigation by monitoring plant performance usually involves detection of surrogates for actual plant stress ([4] [6] [7] and references therein). For example, some recently developed plant based irrigation scheduling approaches are based on sensing crop canopy temperatures exclusively [8]. These approaches assume that an optimum leaf temperature is maintained through mechanistically occult processes resulting in "limited homeothermy" (Mahan and [9] [10]). Variations in these approaches include measuring canopy temperatures in conjunction with the measurement of other environmental variables such as air temperature, dewpoint, wind speed, and solar radiation load [11] [12] or by comparing canopy temperatures of deficit irrigated plants to that of well irrigated plants [13]-[16]. Regardless of the approach used, all plant based irrigationscheduling methods require that both the crop and environmental parameters measured be related to plant stress as a deviation from crop performance and perhaps optimal environmental conditions. 
The rationale for assessing canopy temperatures is based upon the assumption that one of the first symptoms of drought stress is stomatal closure resulting in stomatal limitation to carbon assimilation [17]-[20]. While such approaches have been around for some time (e.g., [13], and references therein), most irrigation scheduling techniques used today are based on the calculated irrigation requirement to replace the water used by evapotranspiration. Such estimates of crop water use are based on free water evaporation or on potential evapotranspiration of standards, such as turfgrass, or alfalfa, adjusted by a crop specific or even by a cultivar specific crop coefficient. Determination of crop coefficients is an empirical experimental exercise that cannot account for plant acclimation to unique environmental conditions during development. Crop coefficients assume a "normally" developing crop and do not take the effects of plant stressors common to semi-arid and arid environments such as drought and high temperature into consideration (e.g., [21]-[24]).

For such reasons the measurement of $\mathrm{CO}_{2}$ and $\mathrm{H}_{2} \mathrm{O}$ fluxes of crop plants that have been allowed to develop under agronomically relevant conditions is essential to understand the impacts of environmental variables on crop productivity, and for refining existing or developing new irrigation strategies. Such measurements are complicated by temporal variation of environmental conditions and of plant physiological processes. Environmental conditions vary diurnally and can exhibit considerable additional variability on the order of minutes from scattered cloud cover for example. Plant water status changes over the course of a day which results in differences in stomatal limitation to assimilation, especially when comparing afternoon to morning photosynthetic rates even at identical light levels (e.g., [14] [25]). Measuring at the field scale with sufficient temporal resolution to relate both crop canopy $\mathrm{CO}_{2}$ and $\mathrm{H}_{2} \mathrm{O}$ exchange with that of such a changing environment, is currently done using eddy covariance or Bowen ratio techniques, which suffer from drawbacks including fetch requirements that effectively limit use to large plots [26]. To develop new irrigation control algorithms, comparison of several small closely spaced plots reduces soil variability between plots and increases the number of plots, both in water treatments and replicates, needed for a given land area (a similar case can be made for comparing species, cultivars or cropping systems). Continuous measurement of canopy level transpiration on smaller plots can be done using electronic soil water measuring techniques or heat pulse sap flow gauges, but these suffer from drawbacks as well. The standard device for evapotranspiration measurement for crop coefficient development is the lysimeter, a costly and permanent structure [24]. Finally, both electronic and gravimetric techniques based soil water measurement approaches do not determine net carbon assimilation $\left(A_{\text {net }}\right)$ rates.

As discussed (above) the ability to make whole canopy estimates of gas exchange by scaling up from leaf level measurements would be extremely useful in estimating canopy conductance and crop coefficients, inferring water use at a the landscape scale, and inferring whole plant stress as a reduction in photosynthesis without resorting to resource intensive and costly approaches. Earlier, we reported relating plant stress as reduced leaf level $\mathrm{A}_{\text {net }}$ to canopy temperature depression [14]. Whether and how whole 
plant $\mathrm{A}_{\text {net }}$ and transpiration could be related to leaf level processes and whole plant stress remained an open question. To help answer this and other questions a device to directly measure crop canopy gas exchange was developed [15] [22]. The objectives of the current work were to determine whether leaf level gas exchange measurements could be scaled to estimate canopy level gas exchange rates in a field setting.

\section{Materials and Methods}

On DOY (Day of Year) 182 at the USDA-ARS Cropping Systems Research Laboratory in Lubbock, TX (33 $\left.35^{\prime} 38.0^{\prime \prime} \mathrm{N},-101^{\circ} 54^{\prime} 10.5^{\prime \prime} \mathrm{W}\right)$ Cotton (Gossypium hirsutum L. var. hirsutum, cvar. FM 9058, Fibermax , Bayer Crop Science ${ }^{2}$ ) seeds were obtained from a local retailer, planted at a depth of $2.5 \mathrm{~cm}$ into North-South oriented rows on raised beds spaced at one meter at a rate of $12 \mathrm{~kg} \cdot \mathrm{ha}^{-1}$. The cultivar is a glyphosate resistant, compact, erect, early maturing variety with normal leaf-type and an intermediate growth and foliage habit. Immediately after planting the field was furrow irrigated with $50 \mathrm{~mm}$ of water to insure even germination and emergence. The resulting average plant population was 15 plants/row meter $\left(150,000\right.$ plants $\left.\cdot \mathrm{ha}^{-1}\right)$. The soil at the location is an Amarillo fine sandy loam (fine-loamy, mixed, superactive, thermic Aridic Paleustalfs). Environmental conditions were recorded by a weather station located $300 \mathrm{~m}$ west of the plots (http://www.lbk.ars.usda.gov/WEWC/weather-pswc-data.aspx).

Individual leaf and whole canopy gas exchange was measured shortly after anthesis on DOY 231. Canopy gas exchange was measure with four CETA chambers described in detail by Baker et al. [15]. Two portable photosynthesis systems (Model LI-6400, LiCor Inc., Lincoln NE, USA) were used to measure leaf level gas exchange. To minimize potential differences in soil moisture arising from differences in water applied during furrow irrigation or through differences in water delivered between SDI tubes (laterals), CETA gas exchange measurements were taken from a single row along $75 \mathrm{~m}$ of the field. One week before beginning measurements, $38 \mathrm{~mm}$ of water was delivered to the cotton through a subsurface drip irrigation system positioned $20 \mathrm{~cm}$ below and along the center of the raised beds through emitters spaced at $60 \mathrm{~cm}$. An additional $50 \mathrm{~mm}$ of water was delivered to the field by subsurface drip over the evenings of DOY 228 and 229 before the gas exchange measurements reported herein began on DOY 231.

With very few exceptions such as the addition of cooling fans to equipment housing, no improvements or modifications were made to the CETA design described earlier so that our data could be more easily compared to that originally reported [15]. A simplified diagram of a CETA cuvette, sans supporting instrumentation, is shown in Figure 1. Briefly, each cuvette consisted of an aluminum framework covered with transparent polycarbonate film defining a working interior $1 \mathrm{~m} \times 0.75 \mathrm{~m} \times 1 \mathrm{~m}(\mathrm{~L} \times \mathrm{W} \times \mathrm{h})$ right rectangular prismatic volume. A programmable data logger (not shown) controlled fan speed and airflow rate to control daytime chamber air temperature to within $0.5^{\circ} \mathrm{C}$ of ambient air temperature using a feedback control algorithm. Differentials between in- 


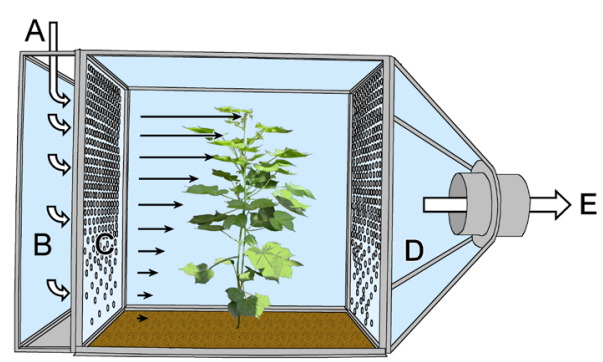

Figure 1. CETA cuvette diagram, adapted from Baker et al. [15]. (A) Opening allowing entry of air into antechamber; (B) Antechamber to reduce effect of wind on airflow through cuvette and undesired mixing of cuvette air with ambient air; (C) Plastic sheet with $2.5 \mathrm{~cm}$ perforation density varying logarithmically with height; (D) Collector; (E) Ducting to variable speed fan.

coming atmospheric and outgoing cuvette $\mathrm{H}_{2} \mathrm{O}$ and $\mathrm{CO}_{2}$ concentrations and airflow through the system were used to calculate canopy transpiration (E) and net assimilation $\left(\mathrm{A}_{\text {net }}\right)$ at $10 \mathrm{~s}$ intervals. Intercepted radiation was tracked by comparing ambient photosynthetically active radiation (PAR) to that received by a four $1 \mathrm{~m}$ linear PAR sensor placed on the soil surface perpendicular to row orientation and about $1.5 \mathrm{~m}$ to the South of each chamber. Intercepted radiation was estimated as the difference between total downwelling PAR measured by a single unobstructed nearby point quantum sensor and the PAR measured by each linear quantum sensors near each CETA chamber.

CETA chambers were deployed along a single row above a single SDI lateral that was located to within $5 \mathrm{~cm}$ of the centerline of the row as seen in Figure 2. Uniform regions of cotton plants were identified along the study zone in which to place the cuvettes (Figure 2(A)). The cuvettes were placed upon heavy rectangular aluminum frames fabricated from $7.5 \times 7.5 \times 0.5 \mathrm{~cm}$ aluminum angle made to accept the base of the CETA cuvettes (Figure 2(A) and Figure 2(B)). These rectangular frames were set into the ground, leveled, and the soil carefully filled in and packed tightly around each side of the frame (Figure 2(B)). Because we were interested only in the crop responses, and because soil gas exchange and respiration would add more variability to the data, the soil was isolated from the chamber atmosphere with a heavy black $0.15 \mathrm{~mm}$ (6 mil) PVC (polyvinylchloride) membrane (Figure 2(C)). The PVC sheeting was fastened to the frame with duct tape to cover the soil surface and prevent $\mathrm{CO}_{2}$ from soil and root respiration processes, and water vapor from soil water evaporation processes from confounding the results. The PVC membrane was carefully fitted around the base of each shoot, and non-toxic duct putty (Gardener Bender \#DS-110, Milwaukee WI) was applied to the PVC sheeting and the base of each stem insure the joints between the stems and the PVC membrane were gas tight (Figure 2(D)). About $20 \mathrm{~kg}$ of tan natural sand (Play Sand, Quickrete Companies, Atlanta GA) was then poured onto the plastic membrane and leveled (Figure 2(E)) to provide ballast for the chamber, prevent the PVC membrane from ballooning under the slight negative pressure at high fan speeds, and to more closely approximate the albedo of the soil in the field (Figure 2(F)). The base of the CETA cuvettes were gasketed with $1 \mathrm{~cm}$ thick self adhesive closed cell neoprene foam weather-stripping and the chambers were then set upon the rectangular 

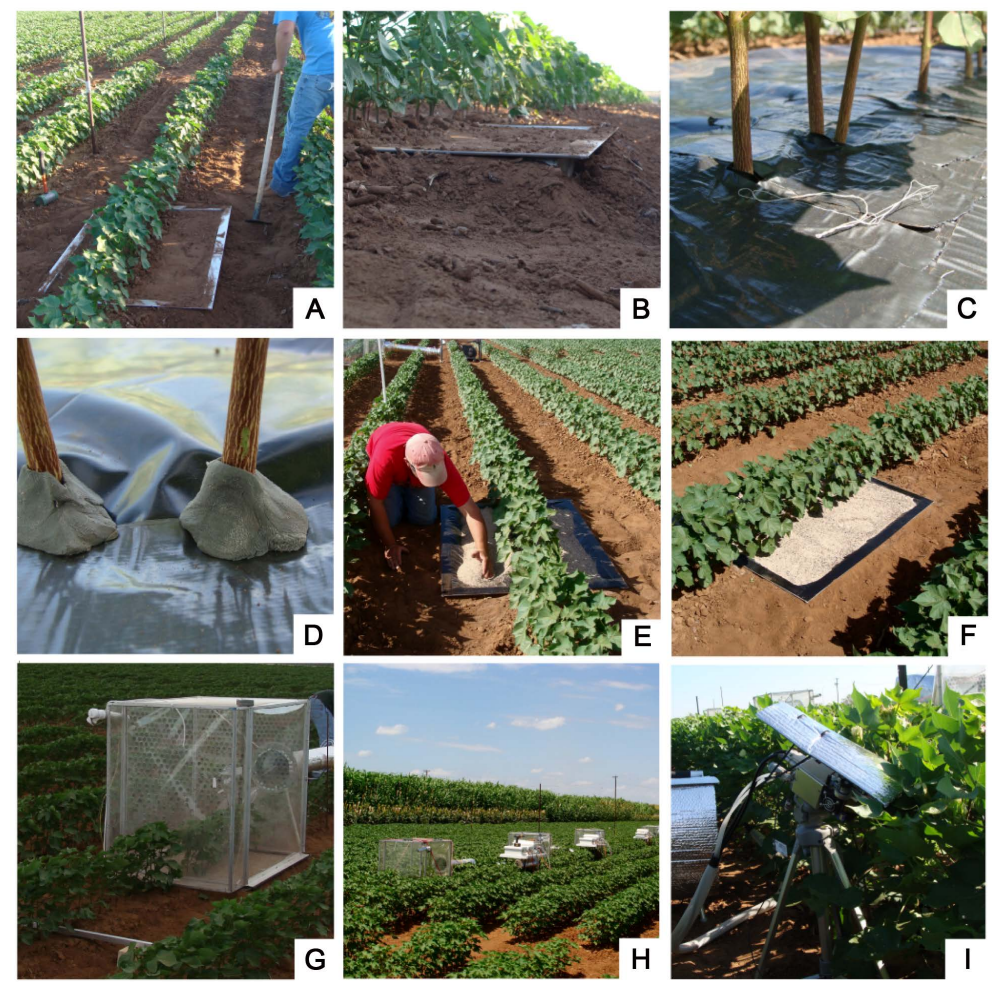

Figure 2. (A) Placing CETA mounting frame in row; (B) Packing soil around frame; (C) Sealing PVC membrane to frame and around plants; (D) Sealing gaps around shoots with putty; (E) Leveling sand in membrane sealed frame; (F) Frame with sand ready to accept CETA cuvette; (G) CETA cuvette mounted on frame. Note external line PAR sensor in left foreground; (H) CETA cuvettes with associated instrumentation field; (I) A leaf level portable photosynthesis cuvette clamped onto a cotton leaf. Silver material is reflective insulation used to reduce heating from solar radiation.

frames (Figure $2(\mathrm{G})$ ), fastened in place with small C-clamps and the automated temperature control and gas exchange measurement system started (Figure 2(H)).

Before removing the chambers from the frames at the end of the experiment, the $\mathrm{Pi}$ tot tube airflow sensors were calibrated with a mechanical anemometer designed to measure flow through heating and air conditioning duct (Model EZ30 EzFlex Thermo-Anemometer, Extech Instruments, Waltham MA, http://www.extech.com/). Data were post processed to calculate $A_{\text {net }}$ and $E$ as described elsewhere [15] [27].

In addition to quantifying the canopy gas exchange by CETA, leaf level gas exchange measurements were made simultaneously with two automated portable photosynthesis systems (Model LI-6400, LiCor Corp, Lincoln NE). The portable photosynthesis system cuvettes were fixed to the most recently fully expanded canopy leaves on two separate cotton plants (Figure 2(I)). Air was drawn in from $0.5 \mathrm{~m}$ above the canopy, through a $20 \mathrm{~L}$ buffer volume and into the inlet of each instrument at a rate of $400 \mathrm{~mL} \cdot \mathrm{min}^{-1}$. The portable photosynthesis systems maintained a block temperature of $28^{\circ}, 400 \mathrm{ml} \cdot \mathrm{min}^{-1}$ flow, and light was delivered to the leaves by blue and red LEDs that tracked ambient PAR by a sensor remotely placed so that it would not be shaded by canopy leaves. Leaf 
level measurements were averaged and logged at 30-s intervals onto a removable flash memory card.

Leaf photosynthesis and transpiration values were scaled to canopy level by estimating leaf area under each CETA cuvette. Weekly throughout the growing season, cotton plants grown in the same field were sampled, taken to a laboratory, and leaf area determined (LI-COR Biosciences, model LI-3100C, Lincoln NE). Leaf area per plant from DOY 209 through DOY 238 was fitted to a simple second-degree polynomial (Sigmaplot 11, Systat Software Inc., San Jose CA, http://www.systat.com). As each CETA cuvette was removed on DOY 236, all the plants were harvested, the total leaf area determined by passing each leaf through the leaf area meter, and the area under each cuvette on DOY 231 estimated using a regression equation derived from the weekly sampling throughout the season of plants grown within the CETA plot.

\section{Results}

The parameters measured by the CETA chambers exhibited little chamber-to-chamber variability. Greater variability was expected due to uncontrollable heterogeneity in soil physical properties and available soil water as we moved across the field and because the estimated leaf areas of the canopies within the cuvettes varied from 1.7 to $2.3 \mathrm{~m}^{-2}$. Transpiration as measured by the CETA system and as approximated by scaling leaf measurements exhibited remarkable agreement (Figure 3) though scaling tended to overestimate canopy transpiration especially during the morning hours. Chamber-tochamber variation as standard error averaged about $9 \%$ during daylight hours, and $20 \%$ over the 24 -h period. Increased variation at night was attributed to reduced differences between inlet and outlet water vapor concentrations.

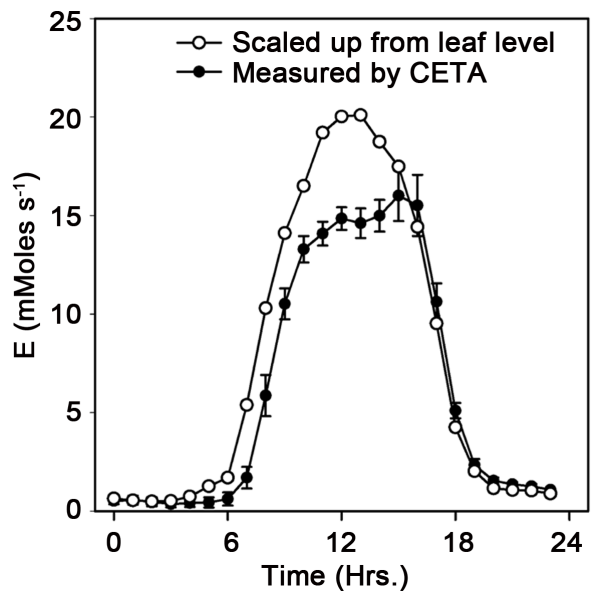

(A)

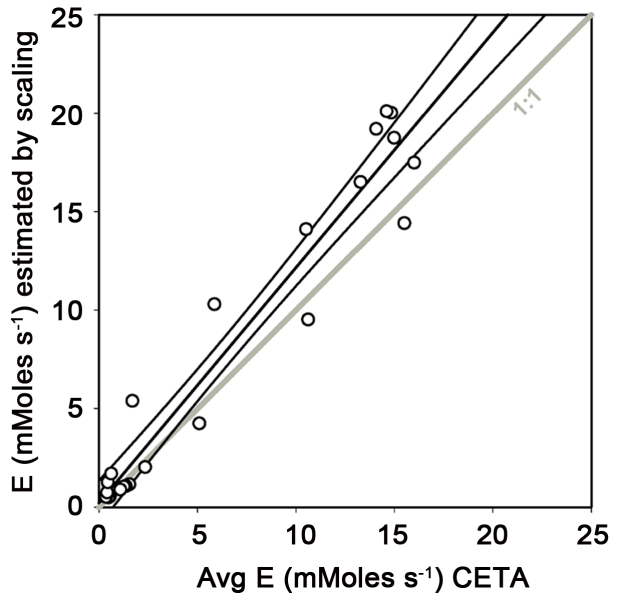

(B)

Figure 3. Canopy transpiration of cotton plants along one meter of row as measured with CETA chambers (open symbols) and as estimated by scaling leaf level gas exchange data up to leaf area within chambers (closed symbols). (A) Diurnal canopy transpiration. Bars are standard error; (B) Comparison of measured to calculated, solid lines are regression, and 95\% confidence interval $\left(\mathrm{E}_{\mathrm{Est}}=1.19 \mathrm{E}_{\mathrm{CETA}}+0.22, \mathrm{r}^{2}=0.94\right)$. Shaded line indicates $1: 1$. 
Attempts to estimate whole canopy net assimilation $\left(\mathrm{A}_{\text {est }}\right)$ by simply scaling leaf level responses by either whole canopy leaf area or by intercepted radiation were less successful and either over- or under-estimated assimilation (Figure 4(A) and Figure 4(B)), depending on whether scaling was based on absorbed photon flux or on a simple leaf area. Nevertheless, measured whole canopy assimilation exhibited a pattern similar to that of radiation absorbed by the canopy. The CETA exhibited considerably greater inter-chamber variation in respiration measurements especially during nighttime (Figure 4(A)).

\section{Discussion}

Attempting to estimate the whole canopy gas exchange responses by scaling up from leaf level responses, generally leads to overestimation because of failure to consider the radiation profile through a canopy [28]. That is, scaling up leaf level measurements by simply multiplying leaf-based measurements by whole canopy leaf area assumes that all leaves within the canopy receive equal ambient radiation. The results presented herein are consistent with this long held contention. An additional error associated with attempting to estimate whole canopy gas exchange as measured by CETA might arise from the chamber design itself. The CETA cuvette antechamber and collector (Figure 2) tends to isolate the canopy within the chamber, so that it might behave as a "clump" of plants or even a single isolated plant. The ends of the row adjacent to the diffuser plates receive more radiation than the canopy towards the middle of the cuvette. Moreover, radiation within chambers is non-uniform because of shading by the aluminum cuvette frame and internal reflections within the cuvette [29]. Overestimation of whole plant transpiration by scaling, as might be expected from leaf to leaf shading

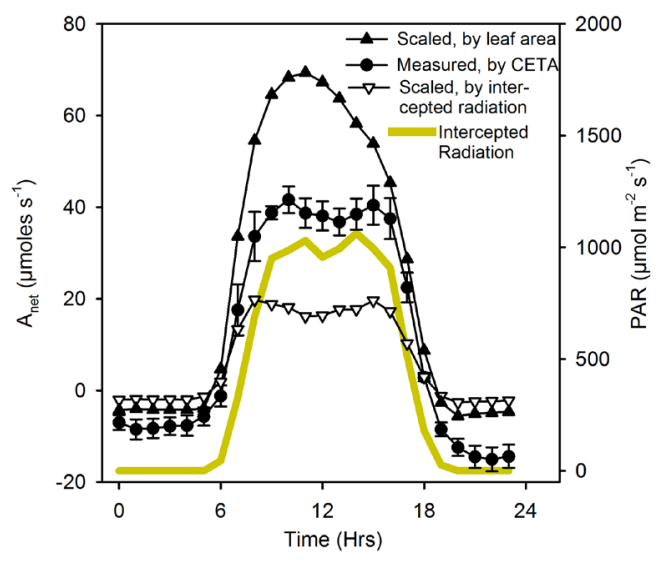

(A)

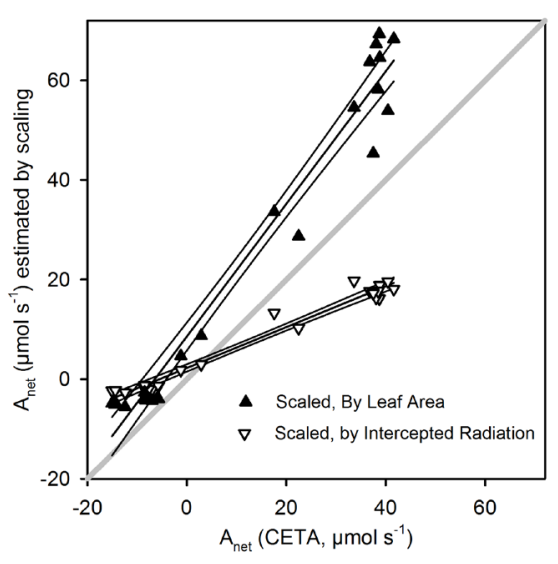

(B)

Figure 4. (A) Net assimilation of canopy within CETA cuvettes determined by CETA (closed circles), estimated by scaling up leaf level assimilation by leaf area in cuvettes (closed triangles), and estimated by scaling up leaf level assimilation by intercepted radiation (open triangles). Heavy dark yellow line in background is intercepted radiation per square meter ground area; (B) Comparison of measured to calculated, solid lines are regression and $95 \%$ confidence interval. Filled symbols are $A_{\text {est }}$ scaled by leaf area $\left(A_{\text {est }}=1.33 \mathrm{~A}_{\text {CETA }}+8.57, r^{2}=0.97\right)$; Open symbols are $A_{\text {est }}$ scaled by intercepted radiation $\left(\mathrm{A}_{\text {est }}=0.41 \mathrm{~A}_{\mathrm{CETA}}+2.25, \mathrm{r}^{2}=0.97\right)$. Shaded line indicates $1: 1$. 
and restriction of air flow though the canopy, occurred primarily in the morning hours. Our group in a greenhouse study observed similar overestimation with a single cotton plant at a similar developmental stage on a digital scale [25]. However, excellent agreement was obtained in the afternoon hours when ambient temperatures were higher and vapor pressure deficit was greater (Figure 3). Taken together, the results of the previous greenhouse experiment [25] and of the current study suggest that whole plant and canopy transpiration rates can be estimated by scaling leaf level transpiration measurements.

However, attempting to estimate canopy net assimilation by scaling was less successful. While the pattern described by intercepted PAR closely resembled that of the the measured canopy $\mathrm{A}_{\text {net }}$ (Figure 4(A)); scaling up leaf level assimilation responses by radiation intercepted by the canopy led to an underestimation of measured whole canopy photosynthetic performance. Conversely, attempting to scale by leaf area alone overestimated assimilation as measured by CETA. This was expected since these approaches neglect the higher efficiency of canopies to the diffuse portion of radiation and the higher apparent quantum efficiency of interior canopy leaves at lower photosynthetic photon flux rates [28].

Because variability in CETA gas exchange measurements between chambers increased at night when both gas exchange and airflow rates through the system were low, error probably arose from either error in air flow measurements or the very small gas concentration differentials between inlet and outlet. Reduced differences between inlet and outlet gas concentrations lead to lower calculated nighttime respiration and transpiration rates. In such situations the ability to detect very small differences in gas concentrations limits accuracy [16] [27]. Even so, agreement between scaled leaf level transpiration measurements seems acceptable even during the nighttime hours. Leaf level measurements may be adequate for estimating physiological drought stress as reduction in transpiration for developing irrigation management or perhaps even for developing crop coefficients without resorting to lysimeters. One benefit of chambers over lysimeters is that we can calculate instantaneous WUE while with lysimeters one usually obtains a seasonal WUE based on water use and a single biomass value at season end.

Because estimating canopy assimilation from leaf measurements is problematic, direct measurement is required if measurements of canopy assimilation is needed. The CETA systems exhibited remarkable chamber-to-chamber consistency under field conditions re-enforcing the feasibility of CETA for longer-term canopy level gas exchange measurements under agronomically relevant conditions. Scaling of nighttime respiration from leaf measurements might be more accurate, though this was not investigated. However, such an approach neglects respiration from the soil surface. In the current study care was taken to isolate the soil from the atmosphere within the cuvette with a heavy polyvinyl chloride membrane so that both soil water evaporation and respiration were neglected. So, while leaf measurements might be useful for estimating whole plant transpiration, at least for cotton in an arid or semi-arid environment, scaling assumptions should probably be empirically checked with direct canopy measurements. Again, 
while scaling can be useful for canopy transpiration estimates, direct measurement of carbon exchange is still required to estimate water use efficiency, i.e., $\mathrm{A}_{\text {net }} / \mathrm{E}$ and in examining other physiological differences associated with carbon exchange between cotton cultivars at the canopy level.

\section{Conclusion}

Transpiration was more closely estimated than assimilation when attempting to scale leaf measurements to canopy level estimates. We suggest this resulted from a relatively large advective component of energy transfer to the leaves [30] and high vapor pressure deficit characteristic of semiarid environments. The ability to estimate canopy level measurements may represent a special case. We anticipate attempts to estimate transpiration in humid environments by scaling up leaf measurements will still prove to be considerably less accurate, because heat transfer to the leaves will be less dependent on advection and high vapor pressure deficits, and more dependent upon solar radiation, which is quite variable within crop canopies.

\section{Acknowledgements}

The technical assistance of Cody Byars and Bill Webb USDA-ARS is acknowledged. This research was supported in part by the Ogallala Aquifer Program, a research consortium between ARS and regional universities.

\section{References}

[1] Camp, C.R. (1998) Subsurface Drip Irrigation: A Review. Transactions of the ASAE, 41, 1353-1367. http://dx.doi.org/10.13031/2013.17309 https://www.ksre.k-state.edu/sdi/abstracts/Camp98.pdf

[2] Solaimalai, A., Baskar, M., Sadasakthi, A. and Subburamu, K. (2005) Fertigation in High Value Crops: A Review. Agricultural Reviews, 26, 1-13. http://arccjournals.com/uploads/articles/ar261001.pdf

[3] Waller, P. and Yitayew, M. (2016) Chemigation. In: Waller, P. and Yitayew, M., Eds., Irrigation and Drainage Engineering, Springer International Publishing, Switzerland, 327-341. http://dx.doi.org/10.1007/978-3-319-05699-9_19

[4] Jones, H.G. (2004) Irrigation Scheduling: Advantages and Pitfalls of Plant-Based Methods. Journal of Experimental Botany, 55, 2427-2436. http://dx.doi.org/10.1093/jxb/erh213

[5] Lichtenthaler, H.K. (1996) Vegetation Stress: An Introduction to the Stress Concept in Plants. Journal of Plant Physiology, 148, 4-14. http://dx.doi.org/10.1016/S0176-1617(96)80287-2

[6] Fernández, J.E. and Cuevas, M.V. (2010) Irrigation Scheduling from Stem Diameter Variations: A Review. Agricultural Forest Meteorology, 150, 135-151. http://dx.doi.org/10.1016/j.agrformet.2009.11.006

[7] Ortuño, M.F., Conejero, W., Moreno, F., Moriana, A., Intrigliolo, D.S., Biel, C., Mellisho, C.D., Pérez-Pastor, A., Domingo, R., Ruiz-Sánchez, M.C., Casadesus, J., Bonany, J. and Torrecillas, A. (2010) Could Trunk Diameter Sensors Be Used in Woody Crops for Irrigation Scheduling? A Review of Current Knowledge and Future Perspectives. Agricultural Water Management, 97, 1-11. http://dx.doi.org/10.1016/j.agwat.2009.09.008 
[8] Mahan, J.R., Burke, J.J., Wanjura, D.F. and Upchurch, D.R. (2005) Determination of Temperature and Time Thresholds for BIOTIC Irrigation of Peanut on the Southern High Plains of Texas. Irrigation Science, 23, 145-152.

http://dx.doi.org/10.1007/s00271-005-0102-9

[9] Mahan, J.R. and Upchurch, D.R. (1988) Maintenance of Constant Leaf Temperature by Plants-I. Hypothesis-Limited Homeothermy. Environmental and Experimental Botany, 28, 351-357. http://dx.doi.org/10.1016/0098-8472(88)90059-7

[10] Upchurch, D.R. and Mahan, J.R. (1988) Maintenance of Constant Leaf Temperature by Plants II. Experimental Observations in Cotton. Environmental and Experimental Botany, 28, 359-366. http://dx.doi.org/10.1016/0098-8472(88)90060-3

[11] Blonquist, J.M.Jr., Norman, J.M. and Bugbee, B. (2009) Automated Measurement of Canopy Stomatal Conductance Based on Infrared Temperature. Agricultural Forest Meteorology, 149, 1931-1945. http://dx.doi.org/10.1016/j.agrformet.2009.06.021

[12] Widmoser, P. (2010) An Alternative to Define Canopy Surface Temperature Bounds. Agricultural Water Management, 97, 224-230. http://dx.doi.org/10.1016/j.agwat.2009.09.012

[13] Jackson, R.D., Kustas, W.P. and Choudhury, B.P. (1988) A Reexamination of the Crop Water Stress Index. Irrigation Science, 9, 309-317. http://dx.doi.org/10.1007/BF00296705

[14] Baker, J.T., Gitz III, D.C., Payton, P., Wanjura, D.F. and Upchurch, D.R. (2007) Using Leaf Gas Exchange to Quantify Drought in Cotton Irrigated Based on Canopy Temperature Measurements. Agronomy Journal, 99, 637-644. http://dx.doi.org/10.2134/agronj2006.0062

[15] Baker, J.T., Van Pelt, S., Gitz III, D.C., Payton, P., Lascano, R.J. and McMichael, B. (2009) Canopy Gas Exchange Measurements of Cotton in an Open System. Agronomy Journal, 101, 52-59. http://dx.doi.org/10.2134/agronj2008.0007x

[16] Baker, J.T., Gitz, D.C., Stout, J.E. and Lascano, R.J. (2015) Cotton Water Use Efficiency under Two Different Deficit Irrigation Scheduling Methods. Agronomy, 5, 363-373. http://dx.doi.org/10.3390/agronomy5030363

[17] Farquhar, G.D. and Sharkey, T.D. (1982) Stomatal Conductance and Photosynthesis. Annual Review of Plant Physiology, 33, 317-345. http://dx.doi.org/10.1146/annurev.pp.33.060182.001533

[18] Yordanov, I., Velikova, V. and Tsonev, T. (2000) Plant Responses to Drought, Acclimation, and Stress Tolerance. Photosynthetica, 38, 171-186.

http://dx.doi.org/10.1023/A:1007201411474

[19] Chaves, M.M., Pereira, J.S., Maroco, J., Rodrigues, M.L., Ricardo, C.P.P., Osório, M.L., Carvalho, I., Faria, T. and Pinheiro, C. (2002) How Plants Cope with Water Stress in the Field? Photosynthesis and Growth. Annals of Botany, 89, 907-916. http://dx.doi.org/10.1093/aob/mcf105

[20] Ashraf, M. and Harris, P.J.C. (2013) Photosynthesis under Stressful Environments: An Overview. Photosynthetica, 51, 163-190. http://dx.doi.org/10.1007/s11099-013-0021-6

[21] Mata-González, R., McLendon, T. and Martin, D.W. (2005) The Inappropriate Use of Crop Transpiration Coefficients $\left(\mathrm{K}_{\mathrm{c}}\right)$ to Estimate Evapotranspiration in Arid Ecosystems: A Review. Arid Land Resource Management, 19, 285-295. http://dx.doi.org/10.1080/15324980590951469

[22] Bryla, D.R., Trout, T.J. and Ayers, J.E. (2010) Weighing Lysimeters for Developing Crop Coefficients and Efficient Irrigation Practices for Vegetable Crops. HortScience, 45, 1597 1604.

[23] Walter, J., Jentsch, A., Beierkuhnlein, C. and Kreyling J. (2013) Ecological Stress Memory and Cross Stress Tolerance in Plants in the Face of Climate Extremes. Environmental and 
Experimental Botany, 94, 3-8. http://dx.doi.org/10.1016/j.envexpbot.2012.02.009

[24] Evett, S.R., Howell Sr., T.A., Schneider, D., Copeland, K.S., Dusek, D.A., Brauer, D.K., Tolk, J.A., Marek, G.W., Marek, T.M. and Gowda, P.H. (2016) The Bushland Weighing Lysimeters: A Quarter Century of Crop ET Investigations to Advance Sustainable Irrigation. Transactions of the ASABE, 59, 163-179. http://dx.doi.org/10.13031/trans.59.11159

[25] Gitz, D.C., Baker, J.T. and Lascano, R.J. (2015) Relating Xylem Cavitation to Gas Exchange in Cotton. American Journal of Plant Sciences, 6, 1742-1751. http://dx.doi.org/10.4236/ajps.2015.611174

[26] Allen, R.G., Pereira, L.S., Howell, T.A. and Jensen, M.E. (2010) Recommended Documentation of Evapotranspiration Measurements and Associated Weather Data and a Review of Requirements for Accuracy. 5th National Decennial Irrigation Conference Proceedings, Phoenix Convention Center, 5-8 December 2010, Paper number IRR10-9970. http://dx.doi.org/10.13031/2013.35828

[27] Baker, J.T., Gitz, D.C. and Lascano, R.J. (2014) Field Evaluation of Open System Chambers for Measuring Whole Canopy Gas Exchanges. Agronomy Journal, 106, 537-544. http://dx.doi.org/10.2134/agronj2013.0449

[28] Amthor, J.S. (1994) Scaling $\mathrm{CO}_{2}$ Photosynthesis Relationships from the Leaf to the Canopy. Photosynthesis Research, 39, 321-350. http://dx.doi.org/10.1007/BF00014590

[29] Kim, S.H., Reddy, V.R., Baker, J.T., Gitz, D.C. and Timlin, D.J. (2004) Quantification of Photosynthetically Active Radiation Inside Sunlit Growth Chambers. Agricultural and Forest Meteorology, 126, 117-127. http://dx.doi.org/10.1016/j.agrformet.2004.06.004

[30] Abdel-Aziz, M.H., Taylor, S.A. and Ashcroft, G.L. (1964) Influence of Advective Energy on Transpiration. Agronomy, 56, 139-142. http://dx.doi.org/10.2134/agronj1964.00021962005600020005x

\section{Submit or recommend next manuscript to SCIRP and we will provide best service} for you:

Accepting pre-submission inquiries through Email, Facebook, LinkedIn, Twitter, etc.

A wide selection of journals (inclusive of 9 subjects, more than 200 journals)

Providing 24-hour high-quality service

User-friendly online submission system

Fair and swift peer-review system

Efficient typesetting and proofreading procedure

Display of the result of downloads and visits, as well as the number of cited articles

Maximum dissemination of your research work

Submit your manuscript at: http://papersubmission.scirp.org/

Or contact ajps@scirp.org 